\title{
Lone Rangers no more: archival cooperation in transition
}

\author{
Charles J. Farrugia
}

\begin{abstract}
Archival cooperation has changed over the last few decades. Building on the author's experience of over 27 years in the archive sector, and on his study and lecturing experiences overseas, the paper focuses on collaboration between archival institutions and sister professions and information management entities in a number of different countries. It explains how archives of small underfunded countries, whose collections nevertheless hold international treasures, can empower their resources through international collaboration. Networks built around specialised themes such as a photographic archives, audio-visual material and the protection of the collective memories of diasporic communities living far from their homeland, are highlighted. Examples of successful new models of collaboration emphasize how archival networking across international borders turns the archivist from a "Lone Ranger" to a member of a large international community, steered by the ICA, guided by ethical and professional principles, and making best use of technology to overcome traditional boundaries.
\end{abstract}

\section{Introduction}

The general theme of the 2016 Seoul ICA Congress, "Archives, Harmony and Friendship", comes at a time when the world's peace, harmony and friendship are under constant threat. Maybe few people consider archives as a driver for a peaceful society; however, we all know that efficient archives management is a requirement for good governance and the latter is a prerequisite for a stable and peaceful society. This paper, originally given as part of a Congress session entitled "Cooperation across disciplines", will discuss how we can build bridges between our profession and parallel ones. This is also an important building block in the wider harmony we aim at. It is an open secret that at times one hears dissonant views between professions; at times territorialism, if not competition between archival institutions, develops.

This paper aims to highlight how archival cooperation has changed over the last few decades. The focus will be on collaboration between archival institutions and sister professions and information management entities. The real life examples of successful new models of collaboration experienced in the National Archives of Malta, which I direct, will emphasize how archival networking across international borders is transforming not only the methods of access to the public but also the type of archivists we need.

Charles J. Farrugia is National Archivist of Malta and Chairman of the Association of Commonwealth Archivists and Records Managers. He was responsible for drafting the National Archives of Malta Act in 2005 and steering reform in the sector, separating archives from libraries and the setting up a new National Archives Agency. He was also the host and organiser of the 41st International Conference of the Round Table on Archives (CITRA) held in Malta in November 2009. He recently gained his doctorate from the University of Aberystwyth, studying models for the assessment of the cultural maturity of national archives institutions in the European Union. 


\section{The isolation of the past}

When, on 9 June 1948, the International Council on Archives was set up, its main aim was to foster a community of archivists and to facilitate collaboration between them and with the outside world. The NGO and international nature of the organisation gave it a hallmark of facilitator and promoter of a bridge-building culture. From the early years, efforts were made to collaborate with other organisations such as IFLA, ICOM and ICOMOS. Notwithstanding these efforts, several years had to pass for the archival profession to face challenges that brought about fundamental changes in the way we operate.

Tangible international cooperation in the archives sector was very minimal up to the 1990s. In his assessment of archival cooperation in Europe and beyond, Patrick Cadell wrote that up to 1991, "there was in general a profound ignorance amongst administrators of what archives were for and what they are about, and ... national archivists were almost as ignorant of how their colleagues operated in other countries".

With all its good intentions, ICA had minimal authority to implement systems and projects. As an organisation, ICA had to cater for the diversity of traditions that make the archival profession so exciting. Even structurally, it groups archivists working within regions or by specialisation. Thus, to some extent, even collaboration between the different Sections and Branches is at times non-existent or hard to foster. However, archives and archivists were still affected by the geo-political and social changes happening in their respective countries and regions. At this point it is worth focusing a bit on the developments that left an important mark on the archives sector within the European Union.

The drive towards a larger and more unified European Union (EU) led to new thinking and an effort towards identifying all those areas which could be stimulated to witness European identity. The political principle of "unity in diversity", which is a cornerstone of EU beliefs, started being applied in areas which till then had not been so much under focus. Initiatives to promote greater cooperation in the field of archives resulted in the publication of the first Report on Archives in the European Union, commonly known as the "Black Book". The various initiatives and developments were further consolidated through the measure of a Council Resolution on 6 May 2003. ${ }^{3}$ Apart from the political message that the EU was appreciating the importance of archives for a democratic environment, the same resolution acknowledged the lack of information sharing among the sector. It also encouraged the setting up of a group of experts with a specific remit, which included "enhance[ing] coordination, information sharing and exchanging of good practice between the archives services".

The end results of these measures were positive in that the EU now has official structures defending the archives domain. These structures still need to be strengthened further, but at least, while respecting the traditions of all countries, there is a common forum where one can discuss the challenges and come up with common policies for the sector at EU level.

In parallel with political changes, the sector was also reacting to constant changes at the

1 CADELL Patrick, 'Lonely but not necessarily alone: archivists and international cooperation' in C. Farrugia (ed.), Guardians of Memory: essays in remembrance of Hella Jean Bartolo Winston, 2008, p. 418.

2 European Commission, Report on archives in the enlarged European Union: Increased archival cooperation in Europe: action plan, Luxembourg: Office for Official Publications of the European Communities, 2006.

3 Council of the European Union, Council Resolution of 6 May 2003 on archives in the member states (2003/C $113 / 02)$.

4 Ibid., point 6 . 
core of the profession - what to teach archivists; what does the public want from archives; new challenges of data protection and freedom of information; and above all new media mainly in the form of digital technology that revolutionised the whole domain. And this brings me to an assessment of the theoretical discussions we had in the profession on whether these changes constituted paradigm shifts that we have to cope with.

\section{Archival paradigm shifts}

The paradigm philosophy was propagated by Thomas Kuhn in his masterpiece The Structure of Scientific Revolutions. ${ }^{5}$ Kuhn argued for a model of progress characterised by periods of conceptual continuity in normal science interrupted by periods of revolutionary science. ${ }^{6}$ This new perspective, refined by Kuhn in further editions, became a cornerstone of theories of change in a number of scientific fields, not least archive studies. ${ }^{7}$

There are a number of different applications of Kuhn's paradigm concept in archival literature. Some researchers have identified paradigm shifts in the history of archival development, while others have associated the transition to electronic records as the main paradigm shift in the domain. In his 1992 ICA Montreal Congress presentation, Charles Dollar said that the change brought about by the need to appraise electronic records was not a reorientation of what archivists do but a new archival paradigm. ${ }^{8}$ However, when summing up the outcomes of one of her research projects, Luciana Duranti argued that old archival concepts continue to have resonance and provide a powerful and internally consistent methodology for preserving the integrity of electronic records. ${ }^{9}$

One of the early contributions on the topic of archival paradigms was made by Hans Hofmann in $1998 .^{10}$ Hofmann identified fundamental shifts within the archival paradigm in four areas:

a. the re-active approach has given way to one that is more pro-active;

b. in the intellectual paradigm of archival theory, the emphasis has shifted from the document remnants of organisations to the original purposes and context of document production;

c. the organisational monopoly of archives is a thing of the past - the documents can be archives at the originating organisations or even in a distributed system;

d. in the area of memory to be preserved, the organisational structure has been replaced by the functional context - in other words - the business transaction.

5 KUHN Thomas, The Structure of Scientific Revolutions, University of Chicago Press, 1962.

6 During revolutions in science, the discovery of anomalies leads to a new paradigm that will change the norms and rules of the process inspiring new research, revisiting old systems and data, leading to new processes and frames of mind.

7 Kuhn issued further editions of his work in 1970 (2nd enlarged edition), 1996 (3rd edition), and 2012 (4th edition).

8 BANTIN Philip C., 'Strategies for managing electronic records: a new archival paradigm? an affirmation of our archival traditions?' in Archival Issues, vol. 23, no. 1, p. 1.

9 DURANTI Luciana and MACNEIL Heather, 'The protection of the integrity of electronic records: an overview of the UBC-MAS research project,' Archivaria 42, pp. 46-67.

1o HOFMANN Hans, 'Lost in cyberspace - Where is the record?' In The Concept of Record, Riksarkivet, Sweden, 1998, pp. 115-130. 
The same theme of archival paradigms was extensively studied by Iván Székely in his 2010 article "The Four Paradigms of Archival History"." Székely's analysis led to a model structured around four paradigms: entitlement-attestation; national; public and global. He elaborated this model by mapping the progression together with the purpose of each paradigm, the key institution exhibiting this paradigm, the owner of the process, the user target audience together with the implications of each. In the phase of global archives the key institution that guarantees access is no longer the archive: it is replaced by the information/communication service provider.

I will return to this concept of an "information/communication service provider" further on when I discuss a case from Malta where the digital technology has transformed access to particular fonds, moved it from the traditional reading room to Family Search centres in the United States and World Wide Web servers in a multitude of countries.

An analysis of archival paradigms has also been conducted by Terry Cook. ${ }^{12}$ In his view, archival paradigms have ranged through four phases and they have seen the archivist transform his/her way of operating. In Cook's view there were institutional transitions from Juridical Legacy, to Cultural Memory, to Societal Engagement and finally to Community Archiving. These paradigms have seen the archivist transform him/herself from a passive curator, to an active appraiser, into a societal mediator and finally to a community facilitator.

Cook discussed in detail the role of archival science in a postmodernist world, saying that postmodernism has challenged archivists everywhere to rethink their discipline and role. On one hand, we have the traditional profession rooted in nineteenth-century positivism with modes of operation originating even earlier in diplomatics; on the other hand, there is the new environment of a postmodern and computerised world. In Cook's view, the change qualifies as a paradigm shift. ${ }^{13}$

Thus, according to Cook, the archivist in the postmodern world needs to be "an active mediator in shaping collective memory through archives". It is a shift towards process rather than product, becoming rather than being, dynamic rather than static, context rather than text, reflecting time and place rather than universal absolutes. In Cook's assessment, at the end of the 1990s, there was no doubt that the archival profession is facing a paradigm shift.

Notwithstanding the identification of the paradigm shift, Cook guards against the idea of entire breaks from the past. He concludes:

11 SZÉKELY Iván, 'The four paradigms of archival history', in Journal of Information Technology Research, 3(4), Oct-Dec 2010, pp. 51-82.

12 COOK Terry, 'Evidence, memory, identity, and community: four shifting archival paradigms', in Archival Science, 2013, 13, pp. 95-120. Cook has a number of works on the issue of archival paradigms: 'What is past is prologue: a history of archival ideas since 1898, and the future paradigm shift' in Archivaria 43 Spring 1997, pp. 17-63; 'From information to knowledge: an intellectual paradigm for archives' in Archivaria 48 (Fall 1999), pp. 64-68.

13 HEDSTROM Margaret and BEARMAN David have analysed the changing scenario with the advent of electronic records and recommended "reinventing archives" entirely by moving focus away from actual custody of records in archives towards controlling records remotely as these reside in on interconnected computers all over the government or business. See 'Reinventing archives for electronic records: Alternative program delivery options', in Margaret Hedstrom ed., Electronic Records Management Program Strategies, Pittsburgh, Archives \& Museum Informatics, 1993, p. 97. 
Not only are paradigms open-ended, overlapping and constantly evolving, the community of archivists that has emerged through these different and overlapping paradigms is itself bound together as a community by the symbiotic interaction of continuity and disruption, continually constructing and deconstructing our mythologies. ${ }^{14}$

There is a common line of thought between the views of Dollar, Hofmann, Cook and Székely supporting the view that archives are experiencing a paradigm shift. But how is this environment of change affecting the archivists and how they collaborate between them and with the outside world?

\section{Drivers for change}

The development of archives in recent decades has been marked by a shift from a local to a global perspective. This can be attributed to a number of factors including unprecedented geo-political, social and economic changes. Writing about these shifts, a previous Keeper of the Public Record Office (now National Archives) of the United Kingdom, Sarah Tyacke, grouped the reasons for this transition from a perspective on three levels: philosophical; technical; and communication through a common language. ${ }^{15}$ I will build around these three types of transition in order to discuss how this shift has affected international archival cooperation.

\section{Philosophical}

Archives as a concept have become fashionable due to the influence of a number of writers amongst whom French philosopher Jacques Derrida whose published works such as Archive Fever discussed the archive and its significance in society. ${ }^{16}$ A number of postmodern thinkers followed in his footsteps, and discussed the archive concept, aware that people nowadays have a need to archive, although they do not call it so. ${ }^{17}$ The wealth of things we do keep and the problems of re-finding information for re-use have focused most people's minds on what should be kept and how to do it. Thus, this new thinking has shifted the onus of information management from an institutional to a personal level. ${ }^{18}$ This philosophical basis was also underlined by an ever-increasing number of governance issues dominating international politics. Wikileaks and the way it hit the international political scene is a case in point - and although we do not associate it directly with archives, it is all about records. Actually, records have become one of the most powerful tools in most electoral campaigns in democratic countries.

Against this background of change and rapid shift from a local to a global perspective the ICA came up with a declaration enshrining the fundamental concepts on archives. The Universal Declaration on Archives (UDA) is not simply a political statement but also the end result of long drawn-out political, academic and professional debates in the sector. ${ }^{19}$

14 COOK, 'Evidence, memory, identity,' p. 117.

15 TYACKE Sarah, 'Views from the Keeper', ARC, no. 172, p. 3, Dec. 2003.

16 DERRIDA Jacques, Archives Fever: A Freudian Impression, London 1996.

17 History of the Human Sciences, Nov. 1998 and Feb. 1999, is dedicated entirely to the concept of the archive.

18 This concept is discussed in BASS J., 'A PIM perspective: leveraging personal information management research in the archiving of personal digital records,' in Archivaria 75, Spring 2013, pp. 49-76.

19 The first version of the UDA was written by archivists in Quebec in 2007 and it was later adopted by the 
The Declaration provides decision-makers world-wide with a powerful and succinct statement about the relevance of archives in society. It highlights administrative transparency and democratic accountability as well as the preservation of collective social memory as fundamental roles of archives. The document is a step forward towards an international consensus on the scope and nature of archives.

The Declaration mentions the concept of "collective social memory". And I must say that memory studies and projects have also provided a driver for change in the profession. Following an electoral pledge by the Maltese government to set up a national oral history archives, my staff have been actively involved with ethnomusicologists, historians, anthropologists and the like to come up with a new approach to our services. And these interactions are changing the way we think, operate and offer services to the public.

\section{Technical}

A second facilitating measure which has helped considerably to bring the concept of archives closer to the masses is the internet. It has opened beyond any boundary what was once restricted to a small group of people. And this holds true for both the archivist and the curators of data as much as the users of the end product. In preparation for this paper I revisited a speech I had made seven years ago at a ceremony in Syracuse, Italy. That event marked the inauguration of an internet portal for Mediterranean Archives. During my speech, "Celebrating Voyages of Discovery", I quoted renowned historian Fernand Braudel who, in his masterpiece The Mediterranean and the Mediterranean World in the Age of Philip II, wrote,

... no history of the sea can be written without precise knowledge of the vast resources of its archives. Here the task would appear to be beyond the powers of an individual historian. There is not one sixteenth-century Mediterranean state that does not possess its charterroom, usually well furnished with those documents that have escaped the fires, sieges and disasters of every kind known to the Mediterranean world. To prospect and catalogue this unsuspected store, these mines of the purest historical gold, would take not one lifetime but at least twenty, or the simultaneous dedication of twenty researchers. Perhaps the day will come when we shall no longer be working on the great sites of history with the methods of small craftsmen. Perhaps on that day it will become possible to write general history from original documents and not from more or less secondary works. ${ }^{20}$

What Braudel was envisaging is nowadays possible via technology. The researcher can reach what Braudel termed "purest historical gold" from the comfort of his/her home or the Wi-Fi connectivity of public places. ${ }^{21}$

Section of Professional Associations within ICA. The Declaration was brought up for approval at the AGM of ICA held on 29 November 2009 in St Julian's, Malta. At that session there was a suggestion by South Africa to postpone its approval in order to bring it closer to UNESCO principles. The Declaration was approved in principle but re-discussed and approved in Oslo Norway on 17 September 2010. Another milestone in its development was its endorsement by the 36 th Session of the General Conference of UNESCO in Paris, on 10 November 2011. See UDA, available, in multiple languages, at www.ica.org/en/universal-declaration-archives, accessed 14 July 2017.

20 BRAUDEL Fernand, The Mediterranean and the Mediterranean World in the Age of Philip II, vol. I, New York, 1972 , p. 18.

21 FARRUGIA Charles, 'Celebrating voyages of discovery'. Speech delivered at the inauguration of the Archivio Storico Multimediale del Mediterraneo, Syracuse, Italy, 31 July 2009. 
Technology has also enabled the profession as a whole and its management bodies to communicate better and faster with the outside world. A few years ago, the Flying Reporters concept was introduced in ICA conferences. ${ }^{22}$ To some extent, it was a way to make best use of the then available technology and communicate faster. This method has been taken over by even faster and more individual tools of communication, making the same participants in ICA events themselves disseminators of information about those events.

\section{Communication}

The world predominance of the English language is another fact which gave archival heritage a global rather than a local dimension. ${ }^{23}$ Furthermore, institutions have invested in multilingual tools and even online translation tools have improved considerably. Ease of travel, investment in scholarships and greater opportunities to carry out internships in different countries have all increased mobility and thus the archives sector has benefitted from this international diversity and expertise.

I remember a time when it was so difficult to find ways to benefit from offers of volunteers who wanted to give their input remotely. Internet technology has made it possible for me to have volunteers of Maltese descent cataloguing remotely from Australia. This means that in terms of labour market or availability of human resources (HR), technology has literally eliminated traditional national borders. Our HR managers no longer think solely of issuing calls for applications, conducting face-to-face interviews and entering into formal contracts of employment, but look at an arsenal of tools like Facebook, Twitter, Skype, crowd sourcing etc. to supplement our workforce, not only in numbers but in the kinds of expertise that is probably still not available just around the corner.

These new realities have also been acknowledged by the ICA. Some years back the Section on Archival Education (ICA-SAE) launched an online database of researchers and research projects to enable better coordination of resources. Efforts were also made to make newcomers into the profession more welcome. I do recall the sense of anxiety I felt during my first international ICA conference in Budapest in 1999. For me it was a world of unknowns and it helps if one gets support with the hundreds of structures within ICA and the thousands of acronyms used in the sector. It seems that support is now much more readily available. I do remember that when I hosted the CITRA conference in Malta there was a breakfast for first time attendees. That seems to have worked well and has now even developed into a mentoring scheme for young professionals. I experienced the system first hand as one of the mentors for one of the newcomers to the last Congress, in Seoul. Under the New Professionals Programme, the Programme Commission (PCOM) is funding the attendance for a number of newcomers to such Congresses. I do feel this is the right way to go - to open up and invest in the younger generation of archivists.

After this summary of the three drivers for change mentioned above, I now focus on the reality of change as it is affecting our daily operations at the National Archives of Malta. I will discuss how two particular collections were accessed by the public 10 years ago, and how they are accessed nowadays.

22 See 'The ICA Flying Reporters,' www.ica.org/en/ica-flying-reporters (accessed 14 July 2017).

23 TYACKE, 'Views from the Keeper'. 


\section{Case study - Magnia Curia Castellaniae}

The first example is the fonds of the Magnia Curia Castelleniae of the Knights of the Order of St John. ${ }^{24}$ This is a fonds of court cases dating back to between 1543 and 1798 consisting of 1,411 volumes. There is intensive research interest in this collection, from local and foreign researchers interested in the legal system, and more importantly for the light the records shed on the social history of the time. Users' access is challenging not only because of the palaeographical skills required, but also due to the fact that the material is catalogued only at volume and not at item level. Ten years ago, anyone interested in this material had to travel to Malta, visit our reading room and work through the volumes.

The second fonds I want to focus on are the Passport applications. This is a fonds of hundreds of thousands of applications to travel, from 1815 up to the present. The material for the post-1915 period also includes photos of applicants. While the skill level needed to read these is minimal, the interest in the material is much more intense with most coming from the thousands of second- and third-generation Maltese in Australia, Canada and all over the diaspora. While up to 10 years ago there was a database to identify the items needed, access still required physical on-site visits to the archives.

During the last decade, both collections were digitised and their metadata re-catalogued in two collaborative international projects - one with the Hill Museum and Manuscript Library (HMML) of Minnesota, the other with the Genealogical Society of Utah. This means that while access to the originals remained in Malta, access to surrogates spread to all the Family Search centres world-wide, and to the HMML virtual site. Concurrently with these developments, the National Archives of Malta was one of the founder partners of the Archives Portal Europe. Thus the material in full digital format also ended up accessible through that portal.

The end result of this project was that material that was once available onsite in Malta is now available with very minimal control on access world-wide, and its metadata is widely available in so many different archival systems. Thus the first big change is: much wider global access. But what interests me more, to drive my point home, is the effect on the profession. In the last few years we have been in constant collaboration with foreign archivists, curators, IT specialists, volunteers etc., collaboratively working on the project. Legal and cultural issues had to be ironed out. Issues such as privacy laws, transferring personal data to third parties, access rights to patrons and so on, had to be discussed within a global, rather than the traditional local perspective. This transition, in the form of collaboration with non-traditional stakeholders and non-traditional professionals, is a most challenging and fruitful sign of the new archival paradigm we are living.

\footnotetext{
24 The Magna Curia Castellaniae was under the jurisdiction of the Master of the Order. Its chief officer, the Castellano,was a Knight of the Order, and the court personnel consisted of a civil judge, a criminal judge, an exchequer, a vice-exchequer, two notaries, and several clerks. It was the largest existing tribunal on the island, and contains considerable information about daily life on the island. It heard both civil suits and criminal trials concerning domestic violence, assault, theft, fights, or appointment of guardians for children. A separate Appellate Court, the Sacra Audientia, heard appeals to its judgments. The Knights were exempt from its jurisdiction because they could be prosecuted within the Order. A full index in 25 volumes by Dr. G. Portelli Carbone was prepared in the late nineteenth century; it was digitized as part of the project.
} 


\section{The impact on professional aspects}

The changes described above have affected the very essence of our profession and the way we think, operate and interact. Standards such as $\operatorname{ISAD}(G)$ have moved from the drawing board into the toolkits of our cataloguing personnel. The shift away from proprietary systems to open data standards is also helping in the move towards the internationalisation of both archivist and client. This is also aided by more opportunities for mobility through internships, scholarships and professional exchanges. All these factors are helping in overcoming the limitations imposed by market economies through sharing of resources. This line of action is imperative for a profession that comparatively speaking will always be small and specialised compared to several other streams of specialisation.

\section{The challenges of the future}

The future still holds important challenges for the profession. Agreeing on international practical and ethical archival principles is imperative. To some extent, this has already been achieved through the endorsement of the Universal Declaration on Archives. But what is its worldwide endorsement and application? Another consideration should be that projects steered by ICA have the inbuilt long term sustainability. This is not always the case. EURONOMOS, a database of archival legislation, is just one of the many projects that fizzled out notwithstanding the amount of energy invested in it.

There is also a great need to develop a global research platform and networks of excellence in areas such as disaster preparedness and digital curation. Going for global instead of local or regional solutions especially in areas of accreditation, development of core competencies and Continuous Professional Development can only strengthen the profession and allow it to withstand the waves of competition from the wide range of information management related professions.

\section{Conclusion}

The real life examples of collaboration discussed here emphasize how archival networking across international borders has turned the archivist from the Lone Ranger to a member of a large international community, steered by the ICA, guided by ethical and professional principles, and making best use of technology to overcome traditional boundaries. The ICA needs a continuous and structured evaluation of its structures to cope with this change in order to fill in the gaps that might exist in collaboration, and in order to ensure that it gets on board the "new type of archivist" who is emerging in this global age of the profession's development. 
